\title{
Studies on the power factor of (Ba,Sr)Co2+xRu4-xO11 compounds
}

\author{
B. Pato-Doldán, M. Sánchez-Andújar, S. Castro-García', M.A. Señarís-Rodríguez
}

Journal of Alloys and Compounds

Volume 509, Issue 5, 3 February 2011, Pages 1529-1533

DOI: 10.1016/j.jallcom.2010.10.153

\section{Abstract}

We have prepared polycrystalline single-phase $A C 02+x R u 4-x O 11(A=S r, B a$; $0 \leq x \leq 0.5)$ using the ceramic method and we have studied their structure, electrical resistivity and Seebeck coefficient, in order to estimate their power factor (P.F.). These layered compounds show values of electrical resistivity of the order of $10-5 \Omega \mathrm{m}$ and their Seebeck coefficients are positive and range from $1 \mu \mathrm{VK}-1(\mathrm{~T}=100 \mathrm{~K})$ to $20 \mu \mathrm{V} \mathrm{K}-1(\mathrm{~T}=450 \mathrm{~K})$. The maximum power factor at room temperature is displayed

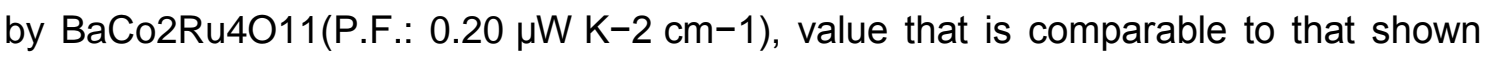
by compounds such as $\mathrm{SrRuO} 3$ and $\mathrm{Sr6Co5O} 15$.

\section{Research highlights}

- $A C 02+x R u 4-x O 11(A=S r, B a ; 0 \leq x \leq 0.5)$ show values of electrical resistivity of the order of $10-5 \Omega \mathrm{m}$ and their Seebeck coefficients are positive and range from $1 \mu \mathrm{V} \mathrm{K}-1(\mathrm{~T}=100 \mathrm{~K})$ to $20 \mu \mathrm{V} \mathrm{K}-1(\mathrm{~T}=450 \mathrm{~K})$.

- BaCo2Ru4O11 shows power factor at room temperature of P.F.: $0.20 \mu \mathrm{W} \mathrm{K-2} \mathrm{cm-1.}$ 


\section{Keywords}

Ruthenates; SrCo2+xRu4-xO11; BaCo2+xRu4-x011; Seebeck coefficient; Power factor

\section{Introduction}

Thermoelectric materials are suitable for devices in which heat can directly be converted into electrical energy or, vice versa, electricity can be used as a source of energy for refrigeration. Thermoelectric devices have several advantages, like being emission free during operation, reliable, noiseless and extremely durable [1]. The efficiency of thermoelectric materials is measured by the figure of merit $(Z)$ or by the dimensionless figure of merit $(\mathrm{ZT})$ - more appropriate because the figure of merit varies with temperature - which has the following formula:

$$
\mathrm{ZT}=\mathrm{S}^{2} \mathrm{~T} \sigma \mathrm{K}-1
$$

where $T$ is the absolute temperature, $\sigma$ is the electrical conductivity of the material, $S$ its Seebeck coefficient and $K$ is its thermal conductivity. In this formula, the product $S^{2} \sigma$, known as the power factor, determines the transport efficiency of the charge carriers.

So far thermoelectric devices with greater application are made of semiconductor elements of post-transition of the fifth and sixth period, such as $\mathrm{Bi}_{2} \mathrm{Te}_{3}$ and $\mathrm{PbTe}$. [2].

Recently, ceramic oxide materials are receiving increased attention as, in addition to the possibility of good thermoelectric behavior, they have the added advantages of higher thermal stability, excellent oxidation resistance, lower cost and weaker toxicity. In this context, Terasaki et al. [3] found that the layered cobalt oxide $\mathrm{NaCo}_{2} \mathrm{O}_{4}-$ formed by layers of octahedral $\mathrm{CoO}_{2}$ with alternating layers of sodium cations - exhibits a relatively high figure of merit at room temperature, which is comparable to a typical thermoelectric material such as $\mathrm{Bi}_{2} \mathrm{Te}_{3}$. Since this discovery, many oxidic systems have been investigated, such as $\mathrm{Ca}_{3} \mathrm{Co}_{4} \mathrm{O}_{9}[4]$ and $\left[\mathrm{Bi}_{1.68} \mathrm{Ca}_{2} \mathrm{O}_{4}\right]^{\mathrm{RS}}\left[\mathrm{CoO}_{2}\right]_{1.69}[5]$ and [6]. Specially interesting are transition metal oxides with highly correlated electrons [7], among them cobalt perovskites $\mathrm{Ln}_{1-} x \mathrm{M} x \mathrm{CoO}_{3} \delta$ and related systems, like for example the doble perovskites $\mathrm{La}_{2-} x \mathrm{Sr} x \mathrm{CoRuO}_{6}[8]$, form an important group. 
In the search for alternative oxide materials with interesting thermoelectric properties we have looked for different series of mixed oxides of cobalt and ruthenium with potentially interesting properties. One of this series is $A \mathrm{ACO}_{2_{+}} x \mathrm{Ru}_{4_{-}} X \mathrm{O}_{11}(\mathrm{~A}=\mathrm{Sr}, \mathrm{Ba})$ which belongs to the family $\mathrm{AM}_{2+} x \mathrm{Ru}_{4-} x \mathrm{O}_{11}(\mathrm{M}=\mathrm{Fe}, \mathrm{Co} ; \mathrm{A}=\mathrm{Sr}, \mathrm{Ba})$. This family has recently attracted interest in the field of spintronics [9] and [10], as some members have been reported to be semiconducting and ferromagnetic at room temperature [9]. These compounds display a bidimensional structure that consists of layers of edgesharing $\left[\mathrm{CoO}_{6}\right]$ or $\left[\mathrm{RuO}_{6}\right]$ octahedra alternating with blocks formed by face-sharing $\left[\mathrm{Co} / \mathrm{RuO}_{6}\right]$ octahedra, $\left[\mathrm{Co} / \mathrm{RuO}_{5}\right]$ trigonal bipyramids and the alkaline earth ions [10] (see Fig. 1 and more details in Section 3).

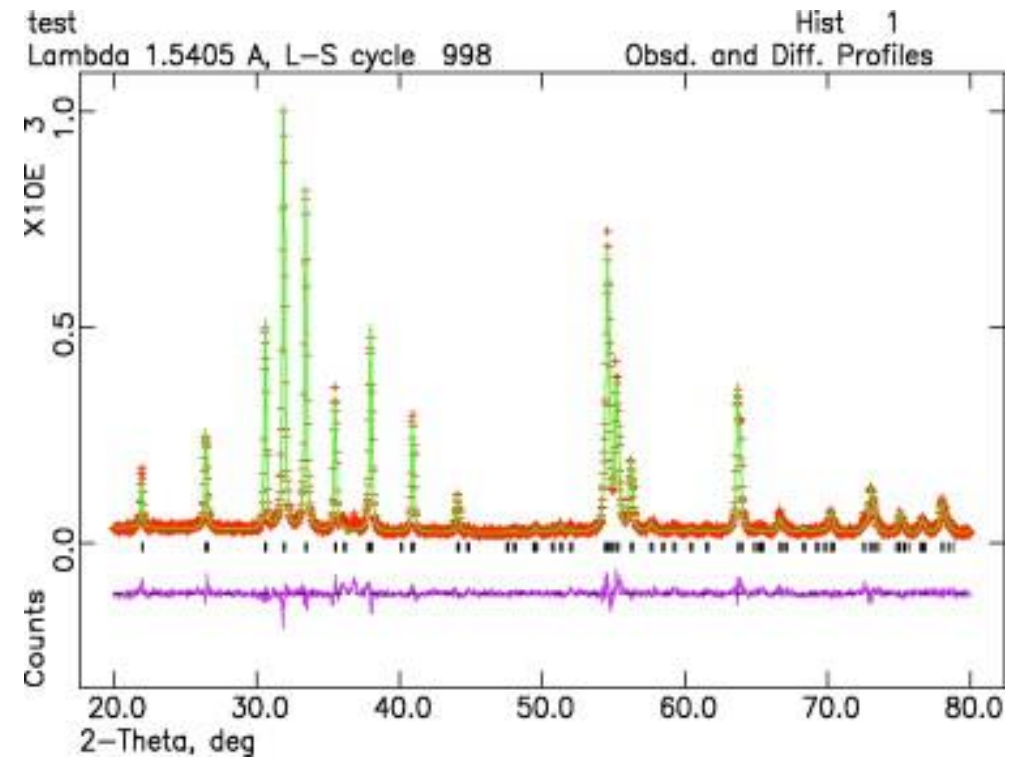

Fig. 1. Room temperature XRPD pattern of the sample $\mathrm{BaCo}_{2} \mathrm{Ru}_{4} \mathrm{O}_{11}$ and corresponding Rietveld refinement. Key: observed (dots), calculated (solid line) and difference (at the bottom) profiles. The tick marks indicate the positions of the allowed Bragg reflections.

Such characteristics could also render them interesting as thermoelectric materials: their electrical properties (low resistivity and high carrier concentration) make them potential candidates to show a large power factor; moreover, their layered structure that bears similarities with $\mathrm{NaCo}_{2} \mathrm{O}_{4}$, which exhibit alternating blocks responsible for the transport and thermal properties - is also adequate to ensure the required low thermal conductivity.

To explore their potential in the field of thermoelectrics, we have focused on $\mathrm{ACo}_{2_{+}} x \mathrm{Ru}_{4_{-}} x \mathrm{O}_{11}$ compounds $(\mathrm{A}=\mathrm{Sr}, \mathrm{Ba})$. According to the literature, polycrystalline samples of $\mathrm{BaCo}_{2} \mathrm{Ru}_{4} \mathrm{O}_{11}$ were first synthesized by Foo et al. [10], authors that also reported that this material behaves like a poor metal with an electrical resistivity of the order of $10^{-5} \Omega \mathrm{m}$ and that it shows ferromagnetic behavior. 
Later on, Shlyk et al. [9] were able to grow single crystals of $\mathrm{BaCo}_{1.85} \mathrm{Ru}_{4.15} \mathrm{O}_{11}$ and $\mathrm{SrCO}_{2} \mathrm{Ru}_{4} \mathrm{O}_{11}$ and made a detailed structural characterization of these compounds. From the electrical point of view, they found that the Ba-compound shows a metallic behavior $(\mathrm{d} \rho / \mathrm{d} T>0)$ and confirmed the ferromagnetic transition that takes place at $105 \mathrm{~K}$. Meanwhile, they reported that the resistivity of the Sr-compound increases with changing slope as temperature decreases below $T_{\mathrm{c}}(115 \mathrm{~K})$.

In this work we have synthesized $A_{C_{2}+} x \mathrm{Ru}_{4-} X \mathrm{O}_{11}(\mathrm{~A}=\mathrm{Sr}, \mathrm{Ba}, 0<x<1)$ materials as polycrystalline samples with the main aim of evaluating their power factor $\left(S^{2} / \rho\right)$ by measuring their electrical resistivity $(\rho)$ and Seebeck coefficient $(S)$.

\section{Experimental}

The $\mathrm{MCo}_{2_{+}} x \mathrm{Ru}_{4-} x \mathrm{O}_{11}(\mathrm{M}=\mathrm{Sr}, \mathrm{Ba}, 0<x<1)$ oxides were prepared by the previously reported ceramic method [10]: stoichiometric amounts of $\mathrm{BaCO}_{3}$ (Fluka, $\geq 99.9 \%$ ) or $\mathrm{SrCO}_{3}$ (Aldrich, $\geq 99.9 \%$ ), $\mathrm{RuO}_{2}$ (Aldrich, 99.9\%) and $\mathrm{CoCO}_{3}$ (Aldrich, 99.7\%), were ground in an agate mortar and heated at $600{ }^{\circ} \mathrm{C}$ for $8 \mathrm{~h}$. The obtained precursor powders were pressed into pellets which were heated in an argon atmosphere at $1050^{\circ} \mathrm{C}$ for $16 \mathrm{~h}$ and slowly cooled $\left(0.5^{\circ} \mathrm{C} / \mathrm{min}\right)$ to room temperature.

The crystal structures of the obtained materials were studied by X-ray powder diffraction (XRPD) in a Siemens D-5000 diffractometer at room temperature using $\mathrm{Cu}$ Ka radiation $(\lambda=1.5418 \AA$ ). The obtained powder diffraction patterns were refined by the Rietveld method with the EXPGUI and GSAS program packages [11] and [12].

The morphology of the samples was studied by scanning electron microscopy (SEM) in a JEOL 6400 microscope.

Electron diffraction and high resolution images were obtained by transmission electron microscopy (HRTEM) in a JEOL 2010 microscope operating at $200 \mathrm{kV}$. For TEM observations suspensions of the samples in ethanol were deposited onto copper grids. Resistivity measurements as a function of temperature were made in the interval $4 \leq T(K) \leq 300$ using a Quantum Design Physical Property Measurement System (PPMS) and a standard D.C. four-probe technique. Cold-pressed pellets cut into cuboids with dimensions of approximately $1.5 \mathrm{~mm} \times 1 \mathrm{~mm} \times 6 \mathrm{~mm}$ were used for these measurements. 
Seebeck coefficients were measured in a home-made device within the temperature range of $77 \leq T(\mathrm{~K}) \leq 450$. The pelletized samples covered with gold were placed between two copper plates and it was measured the potential generated by applying a temperature difference of $1 \mathrm{~K}$ between the plates.

\section{Results and discussion}

\subsection{Sample characterization}

According to XRPD results the samples with nominal composition $\mathrm{BaCo}_{2_{+}} x \mathrm{Ru}_{4_{-}} x \mathrm{O}_{11}(x=0,0.5)$ and $\mathrm{SrCo}_{2} \mathrm{Ru}_{4} \mathrm{O}_{11}$ are single phase materials. Nevertheless, for compositions with higher cobalt content the main phase appears unpurified with secondary phases: either $\mathrm{CoRu}_{2} \mathrm{O}_{4}$ spinel in the case of $\mathrm{Ba}$-compounds or $\mathrm{SrCO}_{1-} x \mathrm{Ru}_{x} \mathrm{O}_{3}$ perovskite in the case of $\mathrm{Sr}$-compounds. To avoid these impurities the synthetic conditions were modified without success. Therefore in what follows we will just refer to the single phase materials $\mathrm{BaCo}_{2_{+}} x \mathrm{Ru}_{4_{-}} X \mathrm{O}_{11}(x=0,0.5)$ and $\mathrm{SrCO}_{2} \mathrm{Ru}_{4} \mathrm{O}_{11}$.

The powder diffraction patterns of these compounds were refined following the crystallographic structure model proposed by Foo et al. [10] by the Rietveld method. Such refinement was relatively complex due to the presence of preferred orientations, whose origin is the anisotropic shape (platelet-like) of the particles. For this situation the GSAS package shows suitable tools to take into account such deviations from an ideal diffraction experiment. The background was fitted with a 10-term polynomial and a pseudo-Voigt function (CW profile function 3) was used for the fitting of the peaks. An example of the corresponding Rietveld refinements is shown in Fig. 1.

These three compounds crystallize in the hexagonal system (space group $P 6_{3} / m m c$ ) and, as already mentioned in Section 1, their structure consists of layers of edgesharing $\mathrm{M}(2) \mathrm{O}_{6}$ octahedra interconnected by face-sharing $\mathrm{M}(1) \mathrm{O}_{6}$ octahedra, $\mathrm{M}(3) \mathrm{O}_{5}$ trigonal bipyramids and the alkaline earth metal, in the ratio 2:3:1:1 (see Fig. 2). The obtained lattice parameters, refined atomic coordinates and derived interatomic distances are in good agreement with that reported in the literature for $\mathrm{BaCo}_{2} \mathrm{Ru}_{4} \mathrm{O}_{11}$ and $\mathrm{SrCo}_{2} \mathrm{Ru}_{4} \mathrm{O}_{11}$ [9] and [10] (see Table 1). 


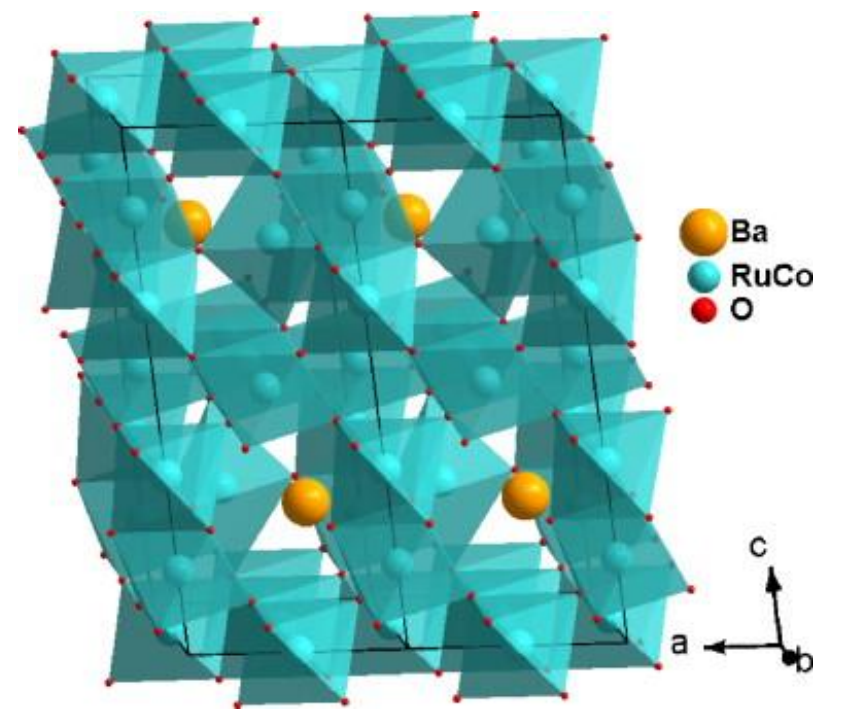

Fig. 2. Crystal structure of $(\mathrm{Ba}, \mathrm{Sr}) \mathrm{Co}_{2-} X \mathrm{Ru}_{4-} X \mathrm{O}_{11}$.

Table 1. Cell parameters $(\AA)$, selected interatomic distances $(\AA)$ and reliability factors as obtained from Rietveld refinement of XRPD data of $\mathrm{BaCo}_{2} \mathrm{Ru}_{4} \mathrm{O}_{11}$, $\mathrm{SrCo}_{2} \mathrm{Ru}_{4} \mathrm{O}_{11}$ and $\mathrm{BaCO}_{2.5} \mathrm{Ru}_{3.5} \mathrm{O}_{11}$.

\begin{tabular}{|c|c|c|c|}
\hline & $\mathrm{BaCo}_{2} \mathrm{Ru}_{4} \mathrm{O}_{11}$ & $\mathrm{BaCO}_{2.5} \mathrm{Ru}_{3.5} \mathrm{O}_{11}$ & $\mathrm{SrCo}_{2} \mathrm{Ru}_{4} \mathrm{O}_{11}$ \\
\hline$a$ & $5.8411(3)$ & $5.8122(3)$ & $5.81392(8)$ \\
\hline \multirow[t]{2}{*}{$c$} & $13.4875(8)$ & $13.4410(1)$ & $13.2576(4)$ \\
\hline & \multicolumn{3}{|c|}{ 4e Site $M(1) O 6$ face sharing octahedron $(M=C o / R u)$} \\
\hline$M(1)-O(1) \times 3$ & $1.94(2)$ & $1.98(2)$ & 1.92(1) \\
\hline \multirow[t]{2}{*}{$M(1)-O(2) \times 3$} & $1.99(1)$ & $2.11(1)$ & $2.08(1)$ \\
\hline & \multicolumn{3}{|c|}{$6 \mathrm{~g}$-Site $\mathrm{M}(2) \mathrm{O} 6$ edge sharing octahedron $(\mathrm{M}=\mathrm{Co} / \mathrm{Ru})$} \\
\hline$M(2)-O(1) \times 4$ & $1.99(2)$ & $1.94(2)$ & $1.99(1)$ \\
\hline \multirow[t]{2}{*}{$\mathrm{M}(2)-\mathrm{O}(3) \times 2$} & $2.07(2)$ & $1.95(1)$ & $1.99(1)$ \\
\hline & \multicolumn{3}{|c|}{ 2d Site $M(3)$ elongated double triangle pyramid $(M=C o)$} \\
\hline$M(3)-O(2) \times 3$ & $1.90(2)$ & $1.74(2)$ & $1.74(1)$ \\
\hline \multirow[t]{2}{*}{$M(3)-O(3) \times 2$} & $2.17(1)$ & $2.26(2)$ & $2.23(2)$ \\
\hline & \multicolumn{3}{|c|}{ Reliability factors } \\
\hline $\mathrm{Chi}^{2}$ & 1.910 & 2.543 & 1.027 \\
\hline$F^{2}$ & 0.127 & 0.116 & 0.115 \\
\hline
\end{tabular}

As expected from the bigger ionic size of $\mathrm{Ba}^{2+}$ compared to that $\mathrm{Sr}^{2+}[13]$, the cell parameters of the Ba-compounds are larger than that of the Sr-compound. It is also worth noting that, in agreement with the results obtained by single crystal studies on analogous compounds $\quad \mathrm{BaFe}_{2} \mathrm{Ru}_{4} \mathrm{O}_{11}, \quad \mathrm{BaMn}_{2} \mathrm{Ru}_{4} \mathrm{O}_{11}, \quad \mathrm{BaLiRu}_{5} \mathrm{O}_{11}$ and $\mathrm{BaCuRu}_{5} \mathrm{O}_{11}[10]$ and [14], these fittings suggest that there is a mixing of $\mathrm{Co}$ and $\mathrm{Ru}$ on the $M(1)$ and $M(2)$ sites, whereas the isolated trigonal pyramidal $M(3)$ site is predominantly occupied by cobalt ions.

Table 1 shows a selection of representative distances in these crystal structures. Comparison of $\mathrm{BaCo}_{2} \mathrm{Ru}_{4} \mathrm{O}_{11}$ and $\mathrm{BaCo}_{2.5} \mathrm{Ru}_{3.5} \mathrm{O}_{11}$ reveals a small deformation of the 
trigonal pyramidal $M(3)$ site $(2 d)$, with an increase on the apical distances and a decrease of the equatorial ones; such deformation of the site occupied predominantly by Co might be linked to the chemistry of the cobalt cations, which can suffer a remarkable modification in their size due to the changes in their electronic configuration.

SEM micrographs (Fig. 3) show that the samples are constituted by poorly sintered platelets with a broad size distribution, within the size diameter range of $0.5-4 \mu \mathrm{m}$. Their hexagonal shape already reflects their internal symmetry.

Fig. 3. SEM micrograph of $\mathrm{SrCO}_{2} \mathrm{Ru}_{4} \mathrm{O}_{11}$ sample.

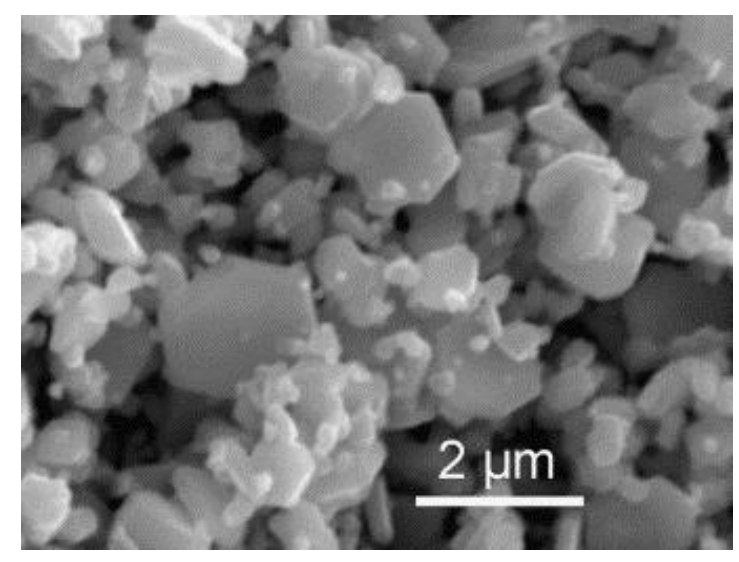

In addition, we have carried out a study of their microstructure by electron diffraction (ED) and HRTEM. In this context, the ED patterns obtained from different crystals in various orientations can all be indexed on the basis of the hexagonal cell (S.G. $P 6_{3} / m m c$ ) seen by XRDP, and the presence of any extra spot, or any "streaking" of the diffraction maxima is not detected (see Fig. 4). As for the HRTEM studies we mainly concentrated in orientations in which the $c$ axis appears on the plane of the projection, trying to detect the presence of possible intergrowths along this axis. These studies were constrained by the fact that the microcrystals oriented along [uv0] zone axis became too thick, therefore it was very difficult to find areas thin enough to obtain good images. Even so, the obtained images show in all cases the regular $d_{001}$ spacing expected for these materials (Fig. 4). Consequently, these microstructural studies confirm the good regularity of the materials and the absence of superstructures and defects (neither local nor extended along the $c$-axis). 
Fig. 4. HRTEM micrograph of $\mathrm{BaCo}_{2} \mathrm{Ru}_{4} \mathrm{O}_{11}$ sample.

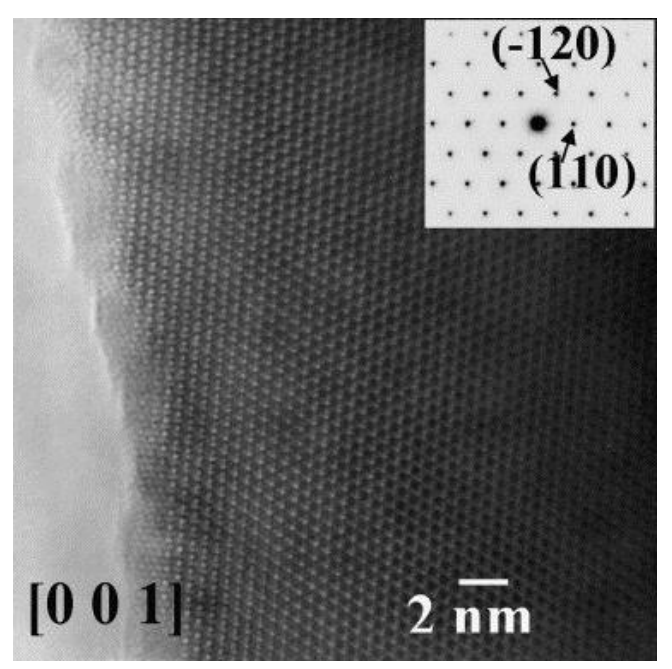

\subsection{Transport properties}

The resistivity of polycrystalline pellets of $\mathrm{BaCo}_{2_{+}} x \mathrm{Ru}_{4_{-}} X \mathrm{O}_{11}(x=0,0.5)$ and $\mathrm{SrCO}_{2} \mathrm{Ru}_{4} \mathrm{O}_{11}$ measured as a function of temperature is shown in Fig. 5.

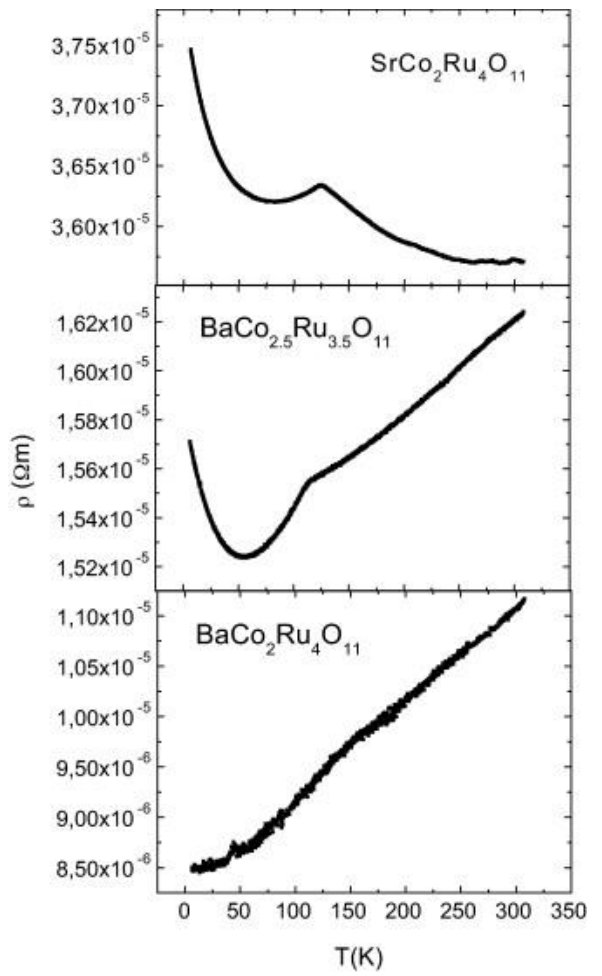

Fig. 5. Resistivity as a function of temperature, corresponding to samples of $\mathrm{BaCo}_{2} \mathrm{Ru}_{4} \mathrm{O}_{11}$, $\mathrm{SrCo}_{2} \mathrm{Ru}_{4} \mathrm{O}_{11}$ and $\mathrm{BaCo}_{2.5} \mathrm{Ru}_{3.5} \mathrm{O}_{11}$.

As it can be seen, the resistivity of the Sr-sample is of the order of $10^{-5} \Omega \mathrm{m}$, slightly higher than in a single crystal [9] and, as in that case, it slowly decreases upon cooling. In addition, and as already reported by Shlyk et al. [9], a small anomaly is detected in the $\rho(T)$ curve of this polycrystalline sample at the ferromagnetic ordering temperature. Then, for $T<50 \mathrm{~K}$ the increase in resistivity is more pronounced. 
In the case of the Ba-samples they both show smaller resistivity values than the Srsample, specially $\mathrm{BaCo}_{2} \mathrm{Ru}_{4} \mathrm{O}_{11}$. Both samples show a metallic behavior ( $\left.\mathrm{d} \rho / \mathrm{d} T>0\right)$ for $T>T_{\mathrm{c}}$, and $\rho(T)$ curve also show a small kink at $T_{\mathrm{c}}$, that is relatively more pronounced in the case of the $\mathrm{BaCo}_{2.5} \mathrm{Ru}_{3.5} \mathrm{O}_{11}$ sample. In this latter case a re-entrant semiconducting behavior is observed for $T<50 \mathrm{~K}$, probably related to the $\mathrm{Ru} / \mathrm{Co}$ disorder.

Such a result indicates that, as in other transition metal mixed oxides [15] the bandwidth of the Ba-compounds is slightly larger than in the equivalent $\mathrm{Sr}$-compounds.

As for the Seebeck coefficient, the three samples show a very similar behavior: an almost linear behavior as a function of temperature with a positive slope typical of metallic behavior. Taking into account the positive sign of the Seebeck coefficient, in the three samples the predominant charge carriers are holes and, in view of the obtained values, their number is quite similar. In this context it is worth mentioning that the real composition of these samples might display small deviations from the given nominal composition.

It should also be mentioned that the magnetic ordering has little impact on the thermoelectric properties of these compounds. Thus, even if the ferromagnetic transition produces a small but noticeable cusp or anomaly in the resistivity of these samples (Fig. 5) there is no significant change in their Seebeck coefficient when crossing $T_{\mathrm{c}}$ ( Fig. 6). The onset of magnetic ordering should decrease the extent of magnetic scattering and possibly increase the mobility of the charge carriers. However, and as seen experimentally, the effect on their thermoelectric behavior is minimal. Since the internal magnetic structure does not greatly influence their thermoelectric properties, an external field will probably also insignificantly alter these.

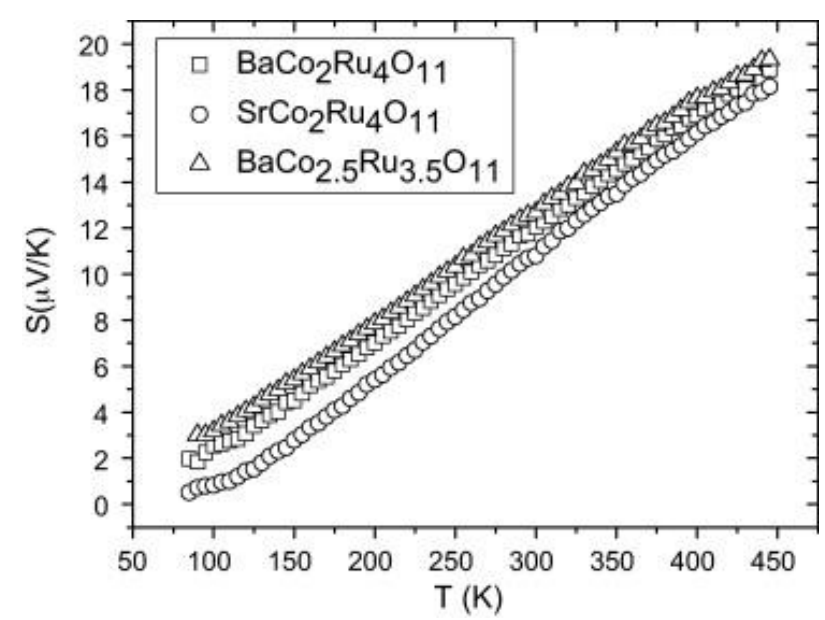

Fig. 6. Temperature dependence of the Seebeck coefficient, corresponding to samples $\mathrm{BaCo}_{2} \mathrm{Ru}_{4} \mathrm{O}_{11}, \mathrm{SrCo}_{2} \mathrm{Ru}_{4} \mathrm{O}_{11}$ and $\mathrm{BaCo}_{2.5} \mathrm{Ru}_{3.5} \mathrm{O}_{11}$. 
Fig. 7 shows the power factor $\left(S^{2} / \rho\right)$ of these materials, that we have calculated from the obtained resistivity and Seebeck data. As it can be seen, the $\mathrm{BaCo}_{2} \mathrm{Ru}_{4} \mathrm{O}_{11}$ sample presents the highest values of the power factor, which reaches a value of $0.2 \mu \mathrm{W} \mathrm{K} \mathrm{K}^{-2} \mathrm{~cm}^{-1}$ at room temperature. The power factor of these compounds are thus smaller than that shown by Terasaki's compound, which reach a value of $50 \mu \mathrm{W} \mathrm{K}^{-2} \mathrm{~cm}^{-1}$ at room temperature, or $\mathrm{Ca}_{3} \mathrm{Co}_{2} \mathrm{O}_{6}$ (P.F.: $16 \mu \mathrm{W} \mathrm{K}^{-2} \mathrm{~cm}^{-1}$ ). Nevertheless, it is comparable to the value of power factor shown by other oxidic compounds at room temperature such as $\mathrm{SrRuO}_{3}\left(P . F .: 4.0 \mu \mathrm{W} \mathrm{K}^{-2} \mathrm{~cm}^{-1}\right.$ ) [16] and $\mathrm{Sr}_{6} \mathrm{CO}_{5} \mathrm{O}_{15}$ (P.F.: $0.52 \mu \mathrm{W} \mathrm{K} \mathrm{K}^{-2} \mathrm{~cm}^{-1}$ ) [17].

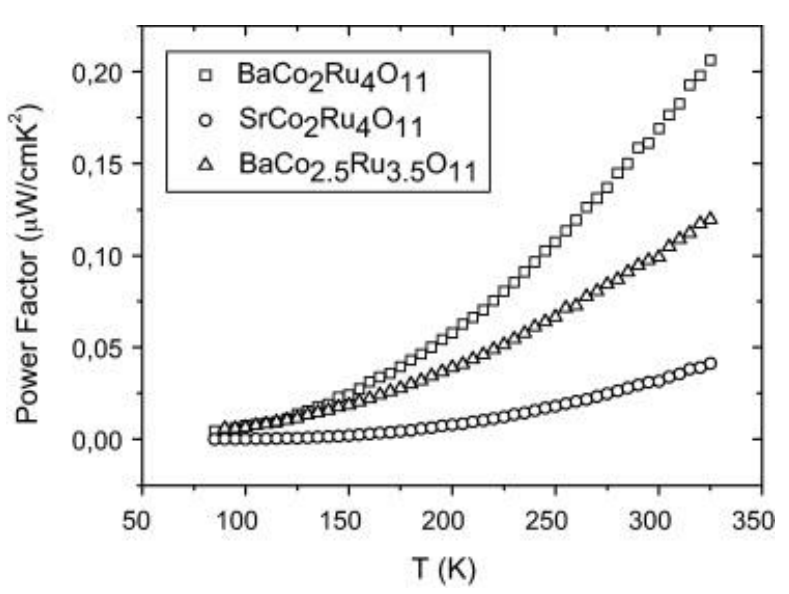

Fig. 7. Temperature dependence of the power factor, corresponding to samples $\mathrm{BaCo}_{2} \mathrm{Ru}_{4} \mathrm{O}_{11}, \mathrm{SrCo}_{2} \mathrm{Ru}_{4} \mathrm{O}_{11}$ and $\mathrm{BaCo}_{2.5} \mathrm{Ru}_{3.5} \mathrm{O}_{11}$.

\section{Conclusions}

Polycrystalline samples of $\mathrm{BaCo}_{2} \mathrm{Ru}_{4} \mathrm{O}_{11}, \quad \mathrm{SrCo}_{2} \mathrm{Ru}_{4} \mathrm{O}_{11}$ and $\mathrm{BaCo}_{2.5} \mathrm{Ru}_{3.5} \mathrm{O}_{11}$ were prepared by the ceramic method and their thermoelectric properties were explored. The values of the electrical resistivity are of the order of magnitude of $10^{-5} \Omega \mathrm{m}$. The Seebeck coefficients are positive in the whole temperature range, and their values range from $1 \mu \mathrm{V} \mathrm{K}^{-1}(T=100 \mathrm{~K})$ to $20 \mu \mathrm{V} \mathrm{K}^{-1}(T=450 \mathrm{~K})$. The maximum value of the power factor at room temperature is $0.20 \mu \mathrm{W} \mathrm{K} \mathrm{cm}^{-1}$ and is displayed by the $\mathrm{BaCo}_{2} \mathrm{Ru}_{4} \mathrm{O}_{11}$ compound. This value is comparable to that shown by other compounds such as $\mathrm{SrRuO}_{3}$ (P.F.:4.0 $\mu \mathrm{W} \mathrm{K}{ }^{-2} \mathrm{~cm}^{-1}$ ) and $\mathrm{Sr}_{6} \mathrm{Co}_{5} \mathrm{O}_{15}$ (P.F.: $0.5 \mu \mathrm{W} \mathrm{K}^{-2} \mathrm{~cm}^{-1}$ ).

\section{Acknowledgements}

The authors acknowledge the financial support from MICINN, Ministerio de Ciencia e Innovación, Spain (Project FEDER MAT 2007-66696 and FPI fellowship of B. PatoDoldán). 


\section{References}

1. D.M. Rowe

General principles and basic considerations

D.M. Rowe (Ed.), Thermoelectrics Handbook, Taylor \& Francis Group, London (2006) (Chap. 1)

2. A.F. loffe

Semiconductor Thermoelements and Thermoelectric Cooling Infosearch Ltd., London (1957)

3. I. Terasaki, Y. Sasago, K. Uchinokura

Phys. Rev. B, 56 (1997), p. R12685

4. M. Mikami, N. Ando, S. Urata, R. Funahashi, E. Guilmeau, D. Chateigner Ceram. Trans., 196 (2006) (Electroceramic Materials and Applications)

5. A. Maignan, S. Hébert, M. Hervieu, C. Michel, D. Pelloquin, D. Khomskii J. Phys.: Condens. Mater., 15 (2003), p. 2711

6. E. Guilmeau, M. Mikami, R. Funahashi

J. Mater. Res., 20 (2005), p. 1002

7. B.C. Sales

Curr. Opin. Solid State Mater., 2 (3) (1997), pp. 284-289

8. P. Tomeš, J. Hejtmánek, K. Nížek

Solid State Sci., 10 (2008), pp. 486-490

9. L. Shlyk, S. Kryukov, B. Shüpp-Niewa, R. Niewa, L.E. De Long Adv. Mater., 20 (2008), pp. 1315-1320

10. M.L. Foo, Q. Huang, J.W. Lynn, T. Wei-Li Lee, I.S. Klimczuk, N.P. Hagemann, R.J. Ong, J. Cava

Solid State Chem., 179 (2006), pp. 563-572

11. A.C. Larson, R.B. von Dreele, "General Structure Analysis System (GSAS)", Los Alamos National Laboratory, Report LAUR (2000) pp. 86-748.

12. B.H. Toby

J. Appl. Crystallogr., 34 (2001), pp. 210-213

13. R.D. Shannon, C.T. Prewitt

Acta Crystallogr. B, 25 (1969), pp. 925-946

14. D. Verdoes, H.W. Zandergen, D.J.W. ljdo Mater. Res. Bull., 22 (1987), p. 1

15. J.B. Goodenough

Prog. Solid State Chem., 5 (1971), pp. 145-399

16. T. Maekawa, K. Kurosaki, H. Muta, M. Uno, S. Yamanaka 
J. Alloys Compd., 387 (2005), pp. 56-59

17. K. Iwasaki, K. Iwasaki, M. Shimada, H. Yamane, J. Takahashi, S. Kubota, T. Nagasaki, Y. Arita, J. Yuhara, Y. Nishi, T. Matsui

J. Alloys Compd., 377 (2004), pp. 272-276 